\title{
DEVELOPMENT OF AN ORAL HYGIENE BEHAVIOR QUESTIONNAIRE FOR ADOLESCENTS BASED ON THE THEORY OF PLANNED BEHAVIOR
}

\author{
Netty Suryanti ${ }^{1}$, Armasastra Bahar ${ }^{2}$, Ali Nina Liche Seniati ${ }^{3}$, Anton Rahardjo ${ }^{4}$ \\ 'Department of Community Dental Health, Faculty of Dentistry, Universitas Padjadjaran, Bandung, Indonesia \\ ${ }^{2}$ Department of Preventive and Public Health Dentistry, Faculty of Dentistry, Universitas Indonesia, Indonesia \\ ${ }^{3}$ Faculty of Psychology, Universitas Indonesia, Indonesia \\ ${ }^{4}$ Department of Preventive and Public Health Dentistry, Faculty of Dentistry, Universitas Indonesia, Indonesia
}

\begin{abstract}
INTRODUCTION: Currently, there is no questionnaire that measures oral hygiene behavior in adolescents based on the theory of planned behavior (TPB) that specifically evaluates tooth-brushing behavior (brushing teeth twice a day: in the morning after breakfast and at night before going to sleep).

Овјестіves: The present study aimed to develop a valid and reliable oral hygiene behavior questionnaire for adolescents based on TPB.

MATERIAL AND METhoDs: The study comprised questionnaire development and testing (validation procedure) stages, followed by field testing (internal consistency, validity, test-retest reliability, and confirmatory factor analysis). RESults: The result of the validity test (alignment between items), including the corrected item-total correlation for all items of the questionnaire was $>0.3$ (all items correlated with the overall scale score). Internal consistency reliability using Cronbach's $\alpha$ indicated good reliability, with an average value of $>0.8$. The intraclass correlation coefficient (ICC) was $>0.73$. The criterion validity result showed that perceived behavioral control and intention correlated significantly with plaque scores $(p<0.001)$ but were not correlated with attitudes and subjective norms. The factorial structure stability for all items was valid for measuring the factor.

ConcLusions: Our adolescent oral hygiene behavior questionnaire based on TPB contains relevant matter that can be understood by students and shows good internal consistency reliability and ICCs. The validity of the criteria was good for perceived behavior control and behavior intentions of oral hygiene and had a valid construct.
\end{abstract}

KEY WORDS: questionnaire, adolescents, oral hygiene, theory of planned behavior, validation.

J Stoma 2020; 73, 3: 129-135

DOI: https://doi.org/10.5114/jos.2020.96941

\section{INTRODUCTION}

In some Asian countries, including Indonesia, dental caries remains a major problem, with oral disease affecting $60-90 \%$ of school children [1]. The Indonesia basic health research reported that the prevalence of caries was $73.4 \%$ in individuals aged $10-14$ years, and $75.3 \%$ in those aged $15-24$ years. The decayed, missing, and filled teeth index value was 1.8 in individuals aged 10-14 years, and 3.1 in those aged 15-24 years [2]. The proportion of daily tooth brushing in the $10-14$ years age group was $96.5 \%$, and $98.5 \%$ in the $15-24$ years old

\section{JOURNAL OF STOMATOLOGY CZASOPISMO STOMATOLOGICZNE}

ADDRESS FOR CORRESPONDENCE: Prof. Anton Rahardjo,

Department of Preventive and Public Health Dentistry, Universitas Indonesia, Jl. Salemba No. 4, 10430, DKI Jakarta, Indonesia, e-mail: antonrahardjo@gmail.com

ReCEIVED: 08.04.2020 • ACCEPTED: 08.06.2020 • Published: 30.06.2020 
age group. However, the percentage of people brushing their teeth for the correct length of time was $2.2 \%$ in the $10-14$ years age group and $3.5 \%$ in the $15-24$ years age group, and most people brushed their teeth in the morning and evening (90.7\%) [2].

Oral hygiene maintenance behavior is an indicator of oral health status. Caries and periodontal disease are the main problems arising from unclean teeth due to plaque. Brushing is one of the most effective ways to reduce plaque, and dental caries can be prevented by regular brushing using fluoridated toothpaste [3]. Brushing twice a day is the recommended practice to prevent and control many dental diseases [4].

The World Health Organization defines adolescents as people aged between 10 and 19 years old [1]. Adolescence is the transition period from childhood to adulthood, characterized by physical, mental, physiological, and intellectual changes, and has an impact on behavior. During adolescence, behavioral patterns, such as negative oral health behaviors develop, which tend to continue into adulthood [5].

The high prevalence of caries observed in adolescents may be attributed to tooth-brushing behavior, which, although may be performed twice a day, is often not carried out at the right time of day (in the morning after breakfast and at night before going to sleep); therefore, the oral health status remains low. In order to reduce the risk of caries and to improve oral health status in adolescents, it is necessary to increase the frequency of tooth brushing at the right time. Results from a study by Rahardjo et al.

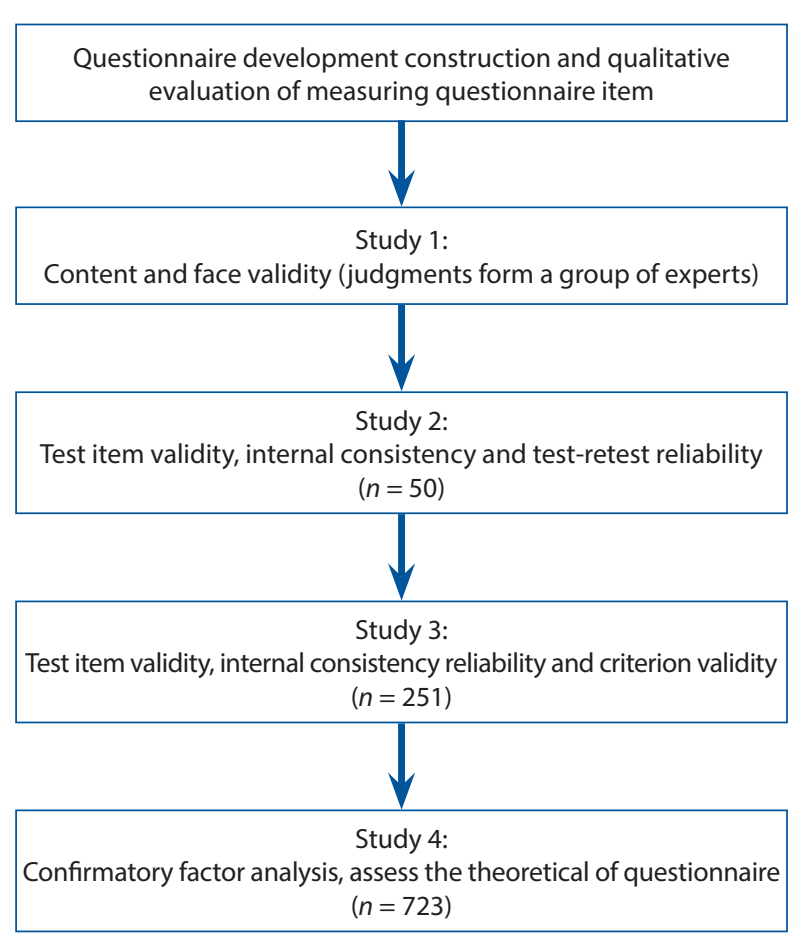

FIGURE 1. Development and field testing of adolescents' oral hygiene behavior questionnaire based on the theory of planned behavior proved that effective education aimed at increasing the duration and frequency of tooth brushing from one time to twice per day is very much needed in Indonesia [6].

Intervention is required to increase the frequency of correct brushing. To develop appropriate intervention strategies, it is necessary to understand determinants of tooth brushing behavior in adolescents to motivate and encourage good and proper brushing behavior that can be performed regularly and maintained until adulthood. The theory of planned behavior (TPB) is a widely used theoretical model that can map the psychological causes of oral health behavior $[7,8]$.

According to Ajzen, the TPB includes three independent determinants of psychological factors of intentional behavior that generally affect behavior, specifically attitudes related to individual behavior evaluation, subjective norms that refer to what other people consider important and belief of what must be done, and perceived behavior control, which is the ease or difficulty perceived by individuals to perform a certain behavior [7].

In Indonesia, no validation scale for oral hygiene behavior is available, which is supported by integrating the measurement of variables included in TPB in one single tool. Therefore, it is appropriate to create and validate a questionnaire for cultural environment in Indonesia.

\section{OBJECTIVES}

The present study aimed to develop a questionnaire to measure adolescent oral hygiene behavior based on the TPB to assess determinants of oral hygiene behavior in adolescents (brushing teeth twice a day, in the morning after breakfast and at night before going to sleep). The results of this assessment may be used to develop appropriate oral health intervention programs for adolescents in Indonesia.

\section{MATERIAL AND METHODS}

This was cross-sectional study, with ethical eligibility obtained from the Independent Institute of the Research Ethics Commission of the Faculty of Dentistry, Universitas Indonesia (protocol no. 070330517). The study comprised of questionnaire development and testing (validation procedure) stages (Figure 1). The participants were adolescents aged 13-15 years from a junior high school in Bandung, who completed the questionnaire to measure adolescent oral hygiene behavior.

\section{DEVELOPMENT QUESTIONNAIRE STAGE}

The development stage involved construction and qualitative evaluation of the measuring questionnaire items as well as preparation in line with the questionnaire construction based on the TPB from Francis et al. [9]. Items 
in the questionnaire were used to evaluate specific oral hygiene behavior (brushing teeth twice a day: in the morning after breakfast and at night before going to sleep) based on the TPB. Qualitative evaluation of the measuring items was performed based on studies and assessments from two oral health experts and one psychologist.

A set of questionnaire items was formulated to assess each construction based on the TPB (attitudes, subjective norms, perceived behavior control, and intention). Attitude toward a behavior indicates a person's overall evaluation of the behavior. It is assumed that two components interrelate, namely beliefs about the consequences of the behavior and the corresponding positive or negative judgments about each feature of the behavior [9].

The development of our model questionnaire included: 1. Attitude assessment related to respondents' opinion about "maintaining good oral hygiene by brushing teeth twice a day in the morning after breakfast and at night before going to sleep". Attitudes were measured using a nine-word statement in a semantic differential format. Direct assessment involved the use of bipolar adjectives. This questioning attitude used a 7-point Likert scale, such as $1=$ unimportant to $7=$ important, $1=$ unpleasant to 7 = pleasant , and so on: unhealthyhealthy, negative-positive, annoying-not annoying, not useful-useful, boring-exciting, painful-painless, and stupid-smart. The total score for respondent's attitude was built by adding nine items (ranging from 9 to 63). A higher score indicated more positive attitude.

2. Subjective norm assessments contained questions like: "What do you think about always remind/tell me to brush my teeth twice a day in the morning after breakfast and at night before going to sleep". Subjective norm variables were evaluated using five items based on reference groups/ individuals, who are closest to students and who tend to apply social pressure regarding behavior to motivate students (parents, dentists, close friends, friends at school, and friends outside of school). This subjective norm used a 7-point Likert scale $(1=$ disagree to $7=$ agree $)$. Total subjective norm scores were constructed by adding five items (ranging from 5 to 35). Higher score indicated more positive subjective norms.

3. Questions concerning perceived behavior control included items on how confident the student was to be able to perform the target behavior (brushing the teeth twice a day: in the morning after breakfast and at night before going to sleep) as well as the difficulty or ease of doing so. Perceived behavioral control was measured using a sum score constructed from three items, i.e., "If I want, I can routinely brush my teeth twice a day in the morning after breakfast and at night before going to sleep", which was answered with endpoints 1 = disagree to 7 = agree; "For me, routine daily brushing twice a day in the morning after breakfast and at night before going to sleep, is... ...to do", with the endpoints $1=$ difficult to $7=$ easy; and "I am able to brush my teeth twice a day in the morning after breakfast and at night before going to sleep every day", which was answered with endpoints $1=$ disagree to 5 = agree . The sum score for respondents' perceived behavior control was constructed by adding the three items (ranging from 3 to 21). Higher score indicated more positively perceived behavior control.

4. Intention can be used as a measure of proximal behavior. The intention was evaluated by one question "Do you have intention to routinely brush your teeth twice a day in the morning after breakfast and at night before going to sleep?" For this single-item measure, the number circled indicated the behavioral intention score [9]. The respondents indicated on 7-point scales with $1=$ no intention to $7=$ strong intention (ranging from 1 to 7 ). Higher score indicated more positive intention.

In all four variable, the mean sum score of each of these scales were assessed via calculation of means, and high sum score indicated a positive attitude, strong perceived approval from significant others, and a high level of perceived behavior control of the ability and strong intention to brush regularly twice a day after breakfast and at night before going to sleep. A list of the questionnaire questions is provided in Table 1.

TABLE 1. The questions asked in the questionnaire

$\begin{array}{ll}\begin{array}{l}\text { Attitudes } \\ \text { towards oral } \\ \text { hygiene }\end{array} & \begin{array}{l}\text { "Maintaining good oral hygiene by brushing teeth twice a day in the morning after breakfast and at night before going to sleep". } \\ \text { According to your assessment of the statement is ............ } \\ \text { (unimportant-important, unpleasant-pleasant, unhealthy-healthy, negative-positive, annoying-not annoying, not useful-useful, } \\ \text { boring-exciting, painful-painless, and stupid-smart) }\end{array} \\ \begin{array}{l}\text { Subjective } \\ \text { norms }\end{array} & \begin{array}{l}\text { What do you think about: "................ always routinely remind/tell me to brush my teeth twice a day in the morning after } \\ \text { breakfast and at night before going to sleep?" (disagree-agree) }\end{array} \\ \begin{array}{l}\text { Perceived } \\ \text { behavior control }\end{array} & \begin{array}{l}\text { "If I want, I can routinely brush my teeth twice a day in the morning after breakfast and at night before going to sleep" (disagree-agree) } \\ \text { to do" (difficult-easy) } \\ \text { "I am able to brush my teeth twice a day in the morning after breakfast and at night before going to sleep every day" (disagree-agree) }\end{array} \\ \text { Intention } & \text { "Do you have intention to routinely brush your teeth twice a day in the morning after breakfast and at night before going to sleep?" } \\ \text { (not intention-strong intention) }\end{array}$




\section{TESTING STAGE (VALIDATION PROCEDURE)}

Study 1 measured the validation procedure (content validity). This referred to the accuracy of measurement based on the content of measuring questionnaire to ensure that the variable items used have fulfilled the whole concept. The compiled variable items were then reviewed, assessed by the oral health experts, and evaluated regarding the composition of each item and its relationship to item variables. Face validity tests were then performed on six junior high school students.

In study 2 , the item validity test was conducted using the corrected item-total correlation (CITC) to estimate the reliability of internal consistency for each scale using Cronbach's $\alpha$ coefficient. Test-retest reliability was demonstrated by intraclass correlation coefficients (ICCs). The questionnaires were completed by 50 junior high school students.

In study 3 , the item validity test was performed using the CITC, reliability test using Cronbach's $\alpha$ reliability coefficient, and criteria validity test. The questionnaire was completed by 251 junior high school students (students who have their second molars), and their oral hygiene (plaque score) was examined, since plaque was the main cause of caries and gingivitis. Plaque score measurement was performed using the O'Leary method, which assessed the presence or absence of plaque on all four tooth surfaces [10]. Plaque scores were used in the criterion validity test. Inter-rater calibration was previously performed by three examiners using the $\kappa$ value of calibration results (0.87). An item validity test (alignment between items) was completed using the SPSS program with CITC. Jones et al. recommended that items with a CITC value of $<0.30$ should be deleted or revised [11]. Therefore, the reliability test of the questionnaire was conducted using Cronbach's $\alpha$ reliability coefficient method, with a minimum cutoff of 0.6, according to Parish et al. [12]. Criteria validity test was performed using Spearman's correlation coefficients, and showed significant correlation values $(p<0.000)$ with plaque scores [13].

Study 4 included a confirmatory factor analysis (CFA) to determine the construct validity (the extent to which

TABLE 2. Socio demographic characteristics of the study sample $(n=723)$

Variable
\begin{tabular}{|l|c|} 
Age & $n(\%)$ \\
\hline 13 years & $401(55.5)$ \\
\hline 14 years & $226(31.3)$ \\
\hline 15 years & $96(13.3)$ \\
\hline \begin{tabular}{l} 
Gender \\
\hline Female
\end{tabular} \\
\hline Male & $344(47.6)$ \\
\hline
\end{tabular}

a questionnaire can be measured based on theoretical construction). The questionnaires were completed by 723 junior high school students. Criteria with a loading factor of $>0.40$ were considered valid in the CFA [14].

\section{RESULTS}

The characteristics of respondents (Table 2) with complete data that could be analyzed were from 723 students of state and private junior high schools in Bandung. A total of 60 respondents dropped out of data because the data was incomplete. The number of male and female respondents was balanced, and most of the respondents were 13 years old.

Study 1 measured the content validity of the questionnaire. Oral health experts indicated that the composition of items in every variable was sufficient, even though some items were modified based on their suggestions, and some words were omitted to increase the clarity of meaning. The face validity test was conducted using six junior high school students, and the students reported experiencing confusion and ambiguity when completing the questionnaire, due to words that were difficult to understand, inaccurate translation, and difficulty in understanding the format of measuring questionnaire. Field observation results showed that some students asked questions because of confusion regarding how to fill out the questionnaire using a Likert scale.

Study 2 involved 50 students for item analysis on oral hygiene behavior measuring devices based on the TPB, with CITC values of $>0.3$ for all items in variables. Cronbach's $\alpha$ values were $>0.7$ for all three variables (attitude, subjective norms, and perceived behavior control), indicating a reliable questionnaire item (Cronbach's $\alpha$ value $>0.6$ confirmed reliability). The test-retest with ICC values was $>0.73$ for the four variables (attitude, subjective norms, perceived behavior control, and intention).

The results of study 3 involving 251 students showed good CITC values $>0.3$ for all questionnaire items (Table 3). However, one item (attitude 2) had a CITC value of $<0.3$. The reliability of all variables presented good reliability, with Cronbach's $\alpha$ values $>0.80$.

In the intention questionnaire in studies 2 and 3, face and content validity were only performed based on expert studies and decisions due to the small number of items. The results of validity of the criteria and the correlation between oral hygiene behavior questionnaires and plaque scores using Spearman's correlation coefficient demonstrated significant results $(p<0.000)$ for perceived behavior control and intention (Table 4$)$. However, this correlation was not significant for attitudes and subjective norms.

Floor or ceiling effects are present, if more than 15\% of respondents achieved the lowest or highest possible score, respectively. Results of floor and ceiling effect from 4 measured variables (only intention) had a high ceiling effect (41.9\%). 
TABLE 3. Internal reliability analysis of the oral hygiene behavior questionnaire based on the theory of planned behavior $(n=251)$

\begin{tabular}{|c|c|c|c|}
\hline \multirow[b]{2}{*}{ TPB item } & \multicolumn{3}{|c|}{ Oral hygiene } \\
\hline & $\begin{array}{l}\text { Corrected } \\
\text { item - total } \\
\text { correlation }\end{array}$ & $\begin{array}{c}\text { Cronbach's } \alpha \\
\text { value if item } \\
\text { deleted }\end{array}$ & $\begin{array}{c}\text { Cronbach's } \\
\alpha \text { value }\end{array}$ \\
\hline Attitude 1 & 0.43 & 0.80 & 0.81 \\
\hline Attitude 2 & 0.21 & 0.83 & \\
\hline Attitude 3 & 0.50 & 0.80 & \\
\hline Attitude 4 & 0.51 & 0.80 & \\
\hline Attitude 5 & 0.57 & 0.79 & \\
\hline Attitude 6 & 0.60 & 0.79 & \\
\hline Attitude 7 & 0.59 & 0.79 & \\
\hline Attitude 8 & 0.53 & 0.79 & \\
\hline Attitude 9 & 0.66 & 0.78 & \\
\hline Subjective norms 1 & 0.33 & 0.83 & 0.80 \\
\hline Subjective norms 2 & 0.36 & 0.85 & \\
\hline Subjective norms 3 & 0.81 & 0.70 & \\
\hline Subjective norms 4 & 0.78 & 0.71 & \\
\hline Subjective norms 5 & 0.76 & 0.72 & \\
\hline $\begin{array}{l}\text { Perceived behavioral } \\
\text { control } 1\end{array}$ & 0.74 & 0.90 & 0.89 \\
\hline $\begin{array}{l}\text { Perceived behavioral } \\
\text { control } 2\end{array}$ & 0.82 & 0.82 & \\
\hline $\begin{array}{l}\text { Perceived behavioral } \\
\text { control } 3\end{array}$ & 0.86 & 0.79 & \\
\hline
\end{tabular}

The results of study 4 for CFA (Table 5) included the items that developed the indicators of attitude, subjective norms, perceived behavior control, and intention were valid, with factor loading values $>0.4$. However, there were two invalid items: subjective norms (1) and perceived behavior control (1). However, the theoretical model agreed with empirical data. The criteria used to test the goodness-of-fit model were $\chi^{2}$ (377.356), GFI (0.94), RMSEA (0.05), and CFI (0.95).

\section{DISCUSSION}

This assessment tool is designed to measure oral hygiene behavior in adolescents, as recommended brushing teeth twice a day: in the morning after breakfast and at night before going to sleep. Study 1 measured the validation procedure (content validity). This refers to the accuracy of the measurement based on the contents of the measurement questionnaire, and oral health experts have assessed that the variable items used have fulfilled the entire concept. Our research involved multistage testing of persistent questionnaire approach. The face validity results showed some revisions to the use of words
TABLE 4. Criterion validity for the oral hygiene behavior questionnaire based on the theory of planned behavior $(n=251)$

\begin{tabular}{|l|c|c|}
\hline \multirow{2}{*}{ Variable } & \multicolumn{2}{c|}{ Total tooth surface with plaque } \\
\hline Attitude & $\boldsymbol{r}$ & $\boldsymbol{p}$ \\
\hline Subjective norm & -0.032 & 0.615 \\
\hline Perceived behavior control & 0.072 & 0.255 \\
\hline Intention & -0.434 & 0.000 \\
\hline
\end{tabular}

TABLE 5. Loading factor value for each valid indicator represents the result of the oral hygiene behavior questionnaire analysis $(n=723)$

\begin{tabular}{|l|c|}
\hline TPB item & Loading factor \\
\hline Attitude 1 & 0.47 \\
\hline Attitude 2 & 0.48 \\
\hline Attitude 3 & 0.69 \\
\hline Attitude 4 & 0.74 \\
\hline Attitude 5 & 0.57 \\
\hline Attitude 6 & 0.77 \\
\hline Attitude 7 & 0.46 \\
\hline Attitude 8 & 0.63 \\
\hline Attitude 9 & 0.74 \\
\hline Subjective norms 2 & 0.52 \\
\hline Subjective norms 3 & 0.93 \\
\hline Subjective norms 4 & 0.91 \\
\hline Subjective norms 5 & 0.85 \\
\hline Perceived behavioral control 2 & 0.77 \\
\hline Perceived behavioral control 3 & 0.80 \\
\hline
\end{tabular}

about oral health that are still common for adolescents and focus on slang terms. The filling method was guided, and an example of how to fill out a questionnaire using a Likert scale was provided.

The results of study 2 with the item validity test showed that all items of the questionnaire were valid. Internal reliability tests (Cronbach's $\alpha$ ) for each variable indicated good values. The results of the test-retest questionnaire were repeated after one week and the results demonstrated good stability. This indicates that the measuring questionnaire was reliable, since it produced the same relative results when the questionnaire was completed again by the same individuals and at different times [15].

In study 3, all the TPB variable items were valid. However, one item from the attitude component (item 2) had a low CITC value (invalid). It may be that the equivalent word was less precise or confusing, which 
was between difficult (scale 1) and fun (scale 7). Therefore, in the questionnaire items, the word 'difficult' will be changed to unpleasant and fun will be changed to pleasant. The reliability test results showed the average Cronbach's $\alpha$ value for all items in all variables as reliable [12]. Content validity tests showed valid, and retest results were stable.

The results of the criterion validity test presented that only the perceived behavior control variable and intention variable were significantly correlated (the higher the questionnaire score the lower the plaque score). Variable attitudes and subjective norms did not correlate. However, the TPB questionnaire is a behavioral concept, all items on the oral hygiene behavior questionnaire can be used together to assess adolescent oral hygiene behavior.

The result of floor and ceiling effect from each measuring instrument showed that the intention score had a ceiling effect. These results illustrate the differences between each respondent, which can be caused by arbitrary answers from respondents or difficulties on answering questions.

Construct validity tests were carried out, one of which was CFA to assess the theoretical construct of the questionnaire (construct validity) of adolescent oral hygiene behavior. The results of the factor analysis showed that the measuring questionnaire had a valid construct (indicators grouped according to their latent variables were consistent in the construct) after the two indicators were excluded due to smaller loading factors. The model based on the goodness-of-fit test fulfilled the criteria; therefore, it was theoretically in accordance with the empirical data. The final results indicated that the questionnaire for adolescent oral hygiene behavior was reliable and valid.

Our questionnaire may be useful to assess the extent of adolescent attitudes and their ability to control the behavior and to identify who can motivate them to regularly brush their teeth twice a day. These results confirm the outcomes of a previous study, and therefore add to the construct validity of the TPB towards oral health behavior. Another similar study on oral hygiene behavior based on the TPB component in older age group and parents of preschool children may explain the proportion of significant differences in some oral hygiene behaviors [8-16].

This questionnaire can help to understand the relevant determinants of adolescent oral hygiene behavior, so that it can be useful for planning an appropriate intervention program. This sample is limited to adolescents of only one city in Bandung. The potential bias can occur because students already know that their teeth would be checked. This could not be avoided because a week before the study, the parents of participants were ought to provide an informed consent. In addition, fill out process was performed together in a classroom, where the possibility of cheating could occur, even though it was monitored by adults.
Future studies are required to assess adolescent populations with different cultures and criteria that affect adolescent oral hygiene behavior. Factors, such as language and ability to read, must be considered when evaluating different ethnic groups and individuals from diverse backgrounds as well as oral health conditions. Furthermore, the questionnaire criteria need to be tested for validity in relation to other health status factors, such as the gingival index and caries index.

\section{CONCLUSIONS}

This preliminary validation study revealed that oral hygiene behavior questionnaire was a reliable and valid tool for measurement of adolescent oral hygiene behavior. Interventions to improve oral hygiene self-care behavior should be based on the TPB, so that the intervention program can be planned appropriately.

\section{ACKNOWLEDGMENT}

This research was supported by the Directorate Research and Community Engagement, Universitas Indonesia. We thank our colleagues from Universitas Indonesia.

\section{CONFLICT OF INTEREST}

The authors declare no potential conflicts of interest with respect to the research, authorship, and/or publication of this article.

\section{References}

1. Petersen PE. The World Oral Health Report 2003: Continuous improvement of oral health in the 21st century - the approach of the WHO Global Oral Health Programme. Community Dent Oral Epidemiol 2003; 31 Suppl 1: 3-23.

2. Kemenkes RI. Riskesdas 2018. Development 2018; 1-220.

3. Vehkalahti MM, Widstrom E. Teaching received in caries prevention and perceived need for best practice guidelines among recent graduates in Finland. Eur J Dent Educ 2004; 8: 7-11.

4. ADA. Cleaning your teeth and gums (oral hygiene). Available at: http://www.ada.org/3072.aspx? current Tab=1\#faq (Accessed: 2010).

5. Friedman HL. The health of adolescents: beliefs and behaviour. Soc Sci Med 1989; 29: 309-315.

6. Rahardjo A, Maharani DA, Kiswanjaya B, et al. Measurement of tooth brushing frequency, time of day and duration of adults and children in Jakarta, Indonesia. J Dent Indones 2015; 21: 85-88.

7. Ajzen I. The theory of planned behavior. Orgnizational Behav Hum Decis Process 1991; 50: 179-211.

8. Buunk-Werkhoven YAB, Dijkstra A, Van Der Schans CP. Determinants of oral hygiene behavior: a study based on the theory of planned behavior. Community Dent Oral Epidemiol 2011; 39: 250-259.

9. Francis J, Eccles MP, Johnston M, et al. Constructing questionnaire based on the theory of planned behaviour. Newcastle upon Tyne, UK: Centre for Health Services Research, University of Newcastle upon Tyne; 2004.

10. Newman MG, Takei HH, Klokkevold PR, Carranza FA. Carranza's clinical periodontology $11^{\text {th }}$ ed [Internet]. Vol. XXXIII, Uma ética para quantos? 2012. 
11. Jones K, Parker E, Mills H, Brennan D, Jamieson LM. Development and psychometric validation of a Health Literacy in Dentistry scale (HeLD). Community Dent Health 2014; 31: 37-43.

12. Parish L, Guilford JP. Fundamental statistics in psychology and education. Br J Educ Stud 2006; 5: 191.

13. Douglas-De-Oliveira DW, Lages FS, Paiva SM, Cromley JG, Robinson PG, Cota LOM. Cross-cultural adaptation of the Brazilian version of the Dentine Hypersensitivity Experience Questionnaire (DHEQ-15). Braz Oral Res 2018; 32: e37.

14. Hair JF Jr, Black W, Babin B, Anderson RE, Tatham R. Multivariate data analysis: a global perspective. $6^{\text {th }}$ ed. New Jersey: Prentice Hall; 2006.

15. Csikszentmihalyi M, Larson R. Validity and reliability of the experience-sampling method. In: Flow and the Foundations of Positive Psychology: The Collected Works of Mihaly Csikszentmihalyi. Springer; 2014

16. Van den Branden S, Van den Broucke S, Leroy R, Declerck D, Hoppenbrouwers K. Measuring determinants of oral health behaviour in parents of preschool children. Community Dent Health 2013; 30: 19-25. 